\title{
Cloning and characterisation of an endosperm specific glutelin B1 promoter from Sri Lankan rice (Oryza sativa L. ssp. indica) variety Bg 250
}

\author{
K. Kajendran ${ }^{1}$, N.V. Chandrasekharan ${ }^{1}$, C.M. Hettiarachchi ${ }^{1}$, A.K. Nanayakkara ${ }^{2}$, D.A.S. Elvitigala ${ }^{3}$ \\ and W.S.S. Wijesundera ${ }^{*}$ \\ ${ }^{1}$ Department of Chemistry, Faculty of Science, University of Colombo, Colombo 03. \\ ${ }^{2}$ Department of Internal Medicine, University of Texas Southwestern Medical Centre, Dallas, TX, 75390, USA. \\ ${ }^{3}$ Department of Basic Science and Social Sciences for Nursing, Faculty of Nursing, University of Colombo, Thalapathpitiya, Nugegoda. \\ ${ }^{4}$ Department of Biochemistry and Molecular Biology, Faculty of Medicine, University of Colombo, Kynsey Road, Colombo 08.
}

\begin{abstract}
Glutelins are the primary source of energy storage in the endosperm of rice grains. Among the glutelin promoters, Glutelin B-1 (GluB-1) is widely studied and used in transgenic rice plants to express recombinant proteins in the endosperm. In this study, three regions: $350 \mathrm{bp}, 1308 \mathrm{bp}$ and $2300 \mathrm{bp}$ of the GluB-1 promoter were PCR amplified from the genomic DNA of $\mathrm{Bg} 250$ rice variety. The amplified fragments were cloned into pGEM ${ }^{\circledR}-\mathrm{T}$ Easy vector for characterisation of $G l u B-1$ promoter. Each region of $G l u B-1$ promoter was separately cloned into the promoterless binary vector pCAMBIA1391Z harbouring the $\beta$-glucuronidase (GUS) reporter gene. Putative transgenic plants were generated by Agrobacterium-mediated gene transformation and confirmed by PCR using nopaline synthase terminator primers. All $G l u B-1$ promoter constructs showed expression of the GUS gene in the endosperm of $\mathrm{T}_{0}$ transgenic plant seeds. The 1308 bp GluB-1 promoter revealed the highest expression as determined by the GUS assay. This indicates the potential of this promoter for expression of recombinant proteins in rice endosperm.
\end{abstract}

Keywords: $G l u B-1$ promoter, transgenic rice.

\section{INTRODUCTION}

The total protein content of rice varies from $8 \%$ - $18 \%$ among different varieties (Shewry, 2007). The rice endosperm is the major site for protein storage. Therefore, the endosperm is a unique platform for the expression of foreign recombinant proteins. Moreover, the rice endosperm tissue occupies more than $90 \%$ of the total seed weight, and represents a stable storage organ that enables the plant to accumulate high amounts of recombinant products (Takaiwa et al., 2007). The use of the endosperm for protein expression has many advantages compared to other expression systems in terms of the cost, large storage ability, ease of controlling the scale of production and the high level of safety in terms of storage of recombinant proteins (Horvath et al., 2000). The rice seed system, as a bioreactor to produce recombinant proteins, has been proven to be a prominent success (Katsube et al., 1999).

The promoter plays a major role in determining the temporal and spatial expression pattern and the transcript level of a gene, which finally governs the amount of expressed recombinant protein ( $\mathrm{Qu}$ et al., 2008). Some strong constitutive promoters, such as the cauliflower mosaic virus $35 \mathrm{~S}$ promoter (CaMV35S), nopaline synthase (NOS) promoter and maize ubiquitin promoter (PZmUbi) are widely used to express protein in transgenic rice seeds (Battraw \& Hall, 1990; Cornejo et al., 1993). Although these promoters have strong activity, they might lack the peak in late seed development that is characteristic of seed-storage protein promoters, which may be required for high-level recombinant

\footnotetext{
* Corresponding author (sulochana@bmb.cmb.ac.lk; iD https://orcid.org/0000-0003-4291-0590)
} 
expression (Drakakaki et al., 2000). In addition, continuous expression of a foreign gene at a high level in all tissues may cause detrimental effects to the host plant. Therefore, a strong endosperm specific promoter could be used to get stable expression of foreign genes than constitutive promoters (Choi et al., 2003). The use of seed-specific promoters has resulted in a high level of protein expression leading to recombinant protein accumulation in seeds (Takaiwa, 2013). In early 2000, the major limitation of using the endosperm to obtain the required level and pattern of expression of recombinant proteins was the lack of strong endosperm specific expression promoters (Qu et al., 2008). Recently, Jeong and Jung (2015) reported the presence of 14 endospermspecific promoters in rice. Among them the glutelin gene promoters of rice are ideal to express foreign genes in rice endosperm because rice glutelin accounts for $\sim 80 \%$ of the total rice seed storage protein.

Genome-wide studies have revealed that there are at least 13 glutelin genes (Qu et al., 2008); hence the high percentage of glutelin expression. The majority of studies on rice glutelin promoters have been focused on identifying cis regulatory elements involved in endosperm specificity and expression patterns (Zheng et al., 1993; Croissant-Sych \& Okita, 1996; Takaiwa et al., 1996; Yoshihara \& Takaiwa, 1996; Wu et al., 1998; Washida et al., 1999).

Among all glutelin promoters of rice, glutelin B-1 $(G l u B-1)$ promoter is the most widely studied (Sarker et al., 2015). It is used as an endosperm specific promoter for expressing foreign genes in rice seeds. The full promoter region of GluB-1 is around $2335 \mathrm{bp}$ (Le \& Takaiwa, 2004). However, a $1.3 \mathrm{~kb}$ region of this promoter has been widely used for the expression of transgenes in rice seeds with satisfactory results (Goto et al., 1999). The $197 \mathrm{bp}$ minimal promoter, upstream of the start site confers endosperm specific expression. This minimal promoter contains GCN4, prolamin box (PROL), AACA and ACGT core motifs. The GCN4 and PROL motifs are conserved in many seed storage protein genes including wheat, barley, rice and maize (Müller \& Knudsen, 1993; Vicente-Carbajosa et al., 1997). The GCN4 motif, prolamin box and AACA motifs are recognised by the bZIP Opaque-2(O2) (Wu et al., 1998), DNA-binding one zinc finger (DOF) class of zinc finger proteins (Mena et al., 1998) and MYB transcription factors, respectively (Suzuki et al., 1998) for seed specific expression. To date, identifying putative cis regulatory elements in promoters has been the main focus in endosperm-specific promoter studies. Nucleotide substitution mutations of the cis regulatory elements in the 197 bp promoter significantly reduces the promoter activity and alters the expression pattern of endosperm. Therefore, it was confirmed that a combination of the cis regulatory elements is a minimal requirement for endosperm specific expression (Wu et al., 1998).

Different sizes $(1.3 \mathrm{~kb}, 2.3 \mathrm{~kb}$ and $2.4 \mathrm{~kb})$ of the GluB-1 promoter have been used in various transgenic approaches to produce higher levels of ectopic gene expressions. These include: $\beta$-carotene in golden rice, human lactoferrin $(h L F)$ gene in Bulgarian barley, soybean ferritin gene in rice, over expression of GABA in transgenic rice cell lines, artificial avidin in rice and over expressed TPC7 antigen in rice (Goto et al., 1999; Katsube et al., 1999; Yoza et al., 2005; Kamenarova et al., 2007; Akama et al., 2009; Wang et al., 2013). All $G l u B-1$ promoters showed seed specific expression in the aleurone and sub aleurone layers (Wu et al., 1998).

Cloned promoter regions become dysfunctional due to reasons such as promoter homology and mutations in $c i s$-acting elements. The functionality of a promoter can be analysed by cloning with a reporter gene such as GUS and transferring the construct into the plant. The expression of the reporter gene gives an indication of the activity of the promoter, both quantitatively and qualitatively.

The present study focused on characterisation of the $G l u B-1$ promoter isolated from $\mathrm{Bg} 250$. The $350 \mathrm{bp}$, $1308 \mathrm{bp}$ and $2300 \mathrm{bp}$ lengths of the GluB-1 promoter were isolated, cloned and characterised to determine the GUS expression in transgenic rice seeds with a view to identifying the most suitable promoter length for transgenic expression in endosperm.

\section{METHODOLOGY}

\section{Cloning of different lengths of GluB-1 promoter}

Genomic DNA was extracted from Bg 250 rice variety using the CTAB method (Sun et al., 2010). Primers were designed to PCR amplify different lengths of the GluB-1 promoter (Table 1) based on the Oryza sativa japonica promoter sequence (Accession number AY427569). Each forward primer (GluB-1F350, GluB-1F1308 and GluB$1 \mathrm{~F} 2300$ ) and reverse primer (GluB-1CR) contained $B a m \mathrm{HI}$ and EcoRI restriction sites respectively at the 5' end. The final concentrations of the PCR components were; $50 \mathrm{ng}$ of template DNA, $2.5 \mathrm{mM} \mathrm{MgCl}, 0.2 \mathrm{mM}$ dNTPs, $0.5 \mu \mathrm{M}$ of each primer and $1 \mathrm{U}$ of GoTaq ${ }^{\circledR}$ DNA polymerase (Promega, USA). The PCR conditions were as follows: initial denaturation at $95^{\circ} \mathrm{C}$ for $5 \mathrm{~min}$ and 35 cycles of denaturation at $95^{\circ} \mathrm{C}$ for $1 \mathrm{~min}$, annealing for $30 \mathrm{~s}$ and an extension at $72^{\circ} \mathrm{C}$. 
Table 1: List of primers for the amplification of different lengths of the GluB-1 promoter

\begin{tabular}{ll}
\hline Primer name & Primer sequence 5' to $3 '$ \\
\hline${\text { GluB- } 1 \mathrm{~F}_{350}}^{\prime}$ & GGATCCCTCAAGCATAAGAGCTTTATGGTGC \\
GluB-1F $_{1308}$ & GGATCCACTGAATAGATCTCGATTTTTGAGGAATTT \\
GluB-1F & GGATCCACAGATTCTTGCTACCAA \\
GluB-1CR & GAATTCAGCTATTTGTACTTG CTTATGGAAACTTAACCT \\
\hline
\end{tabular}

The annealing temperature and the time of extension are given in Table 2. The final extension was carried out at $72{ }^{\circ} \mathrm{C}$ for $10 \mathrm{~min}$.

Table 2: Annealing temperatures and extension times of primers for the amplification of different lengths of the GluB-1 promoter

\begin{tabular}{llr}
\hline Combination of primers & $\begin{array}{c}\text { Annealing } \\
\text { temperature }\left({ }^{\circ} \mathrm{C}\right)\end{array}$ & Extension time \\
\hline
\end{tabular}

\begin{tabular}{|c|c|c|}
\hline GluB- $1 F_{2300}$ and GluB-1CR & 54 & $2 \mathrm{~min}$ and $30 \mathrm{~s}$ \\
\hline GluB- $1 F_{1308}$ and GluB-1CR & 58 & $1 \mathrm{~min}$ and $30 \mathrm{~s}$ \\
\hline GluB-1F ${ }_{350}$ and GluB-1CR & 58 & $30 \mathrm{~s}$ \\
\hline
\end{tabular}

The amplified GluB-1 promoter fragments (350 bp, $1308 \mathrm{bp}$ and $2300 \mathrm{bp}$ ) were eluted and purified using the Wizard ${ }^{\circledR}$ SV Gel and PCR Clean-Up System (Promega, USA). The eluted DNA was then separately cloned into pGEM $^{\circledR}$-T Easy vector (Promega, USA) according to the manufacturer's instructions. Randomly selected clones were used to extract recombinant plasmids. They were then digested by EcoRI (Promega, USA) to confirm the presence of the insert. Subsequently, the recombinant clones were custom sequenced using vector specific primers, SP6 and T7 (Macrogen, Korea) to confirm the promoter sequences.

\section{Promoter sequence analysis}

The sequence dataset was analysed using BioEdit software (version 7.0) while the homology searches were performed using BLAST at the NCBI website (http://blast.ncbi.nlm.nih.gov). PLACE software (http:// www.dna.affrc.go.jp/PLACE/) was used to detect cis regulatory elements in the GluB-1 promoter sequence (Higo et al., 1999).

\section{Construction of plant transformation vectors}

The binary vector pCAMBIA1391Z was used in this study (Cambia, Australia). Sequence confirmed different lengths of the GluB-1 promoter containing recombinant pGEM $^{\circledR}$-T Easy vector and pCAMBIA $1391 Z$ vector were double digested with EcoRI and BamHI. Double digested promoter inserts and the pCAMBIA1391Z vector were ligated using T4 DNA ligase (Promega, USA) and separately transformed into E. coli (JM109) competent cells according to standard protocols (Sambrook \& Russel, 2000). The recombinant clones were confirmed by colony PCR using specific primers (Table 1). All promoter constructs (Figure 1) were then transformed into Agrobacterium GV3101 by the freeze thaw method (Holsters et al., 1978). The transformants were selected by colony PCR using specific primers (Table 1).

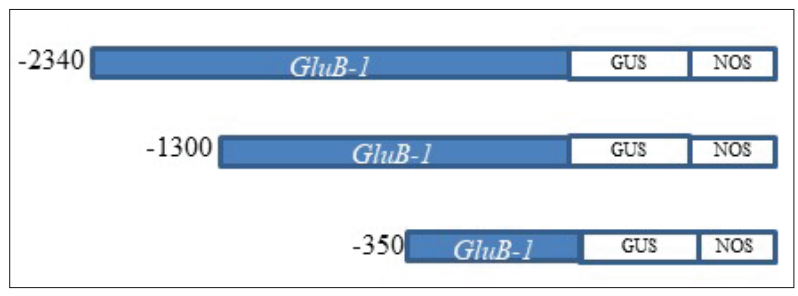

Figure 1: Binary vector pCAMBIA1391Z constructs of the GluB-1 promoter of different lengths

\section{Regeneration of transgenic rice}

The different media used for the regeneration of transgenic rice plants were prepared as reported by Kajendran et al., in 2019. Rice variety Bg 250 was used to transform the constructs carrying different lengths of GluB-1 promoter. De-husked mature seeds were surface sterilised and plated directly on callus induction medium. The plates were then incubated at $28{ }^{\circ} \mathrm{C}$ in 
the dark for 21 days for the callus to grow. Meanwhile, Agrobacterium tumefaciens carrying vector constructs of different $G l u B-1$ promoter lengths were separately cultured in LB broth medium containing kanamycin $(50 \mathrm{mg} / \mathrm{L})$ and rifampicin $(50 \mathrm{mg} / \mathrm{L})$ at $28{ }^{\circ} \mathrm{C}$ until $\mathrm{OD}_{600}$ reached 1.0. The bacteria were then harvested by centrifugation $(3250 \mathrm{~g})$ and the pellet was re-suspended in Agrobacterium re-suspension medium. The fully grown calli were immersed in the above re-suspended Agrobacterium for $10 \mathrm{~min}$. The excess Agrobacterium suspension was removed by filtration and the calli were blotted dry prior to transferring them into the cocultivation medium. After 3 days, the calli were washed with sterilised distilled water followed by repeated washing with aqueous solutions of cefotaxime (containing $1 \mathrm{~g} / \mathrm{L}, 750 \mathrm{mg} / \mathrm{L}$ and $500 \mathrm{mg} / \mathrm{L}$ cefotaxime, respectively) to remove bacteria (Agrobacterium). The calli were then allowed to proliferate in callus induction medium. After 3-4 weeks, proliferated calli were transferred into hygromycin (Sigma, USA) selection medium. Healthy calli were sub cultured on shoot generation medium for $2-3$ weeks in the dark. The calli were then incubated under light to generate shoots. Fully-grown shoots were sub cultured on root generation medium to induce root growth. The one-month-old plants were then transferred to sterile soil. Acclimatised plants continued to grow in the green house. The transformed plants were confirmed by PCR analysis using Nos terminator primers under the following PCR conditions: initial denaturation at $95{ }^{\circ} \mathrm{C}$ for $5 \mathrm{~min}$ and 35 cycles of denaturation at $95^{\circ} \mathrm{C}$ for $30 \mathrm{~s}$, annealing at $58{ }^{\circ} \mathrm{C}$ for $30 \mathrm{~s}$, extension at $72{ }^{\circ} \mathrm{C}$ for $30 \mathrm{~s}$ followed by a final extension at $72{ }^{\circ} \mathrm{C}$ for $5 \mathrm{~min}$.

\section{Analysis of GUS gene in transgenic plants}

Leaf discs, root and matured seeds from a $\mathrm{T}_{0}$ transgenic plant (of different GluB-1 promoters) and non-transgenic $\mathrm{Bg} 250$ rice plants were collected and screened histochemically to analyse the expression of the GUS gene. Transgenic seeds, leaf discs and roots were submerged in fixation buffer ( $2 \%$ formaldehyde, $0.05 \%$ Triton X-100 and $50 \mathrm{mM}$ sodium phosphate), vacuum infiltrated for $10 \mathrm{~min}$ on ice and kept at room temperature $\left(28^{\circ} \mathrm{C}\right)$ for $10 \mathrm{~min}$. The fixation buffer was removed and washed twice with $50 \mathrm{mM}$ sodium phosphate buffer. Thereafter, the seeds, leaf discs and root samples were stained with $1.5 \mathrm{mM}$ of 5-bromo-4-chloro-3-indolyl- $\beta$ D-glucuronic acid (X-gluc), $50 \mathrm{mM}$ sodium phosphate and $0.1 \%$ Triton $\mathrm{X}-100$ by vacuum infiltrating for $5-10$ min and kept at $37^{\circ} \mathrm{C}$ overnight in the dark prior to visualisation (Jefferson, 1987; Ratnayake \& Hettiarachchi, 2010)

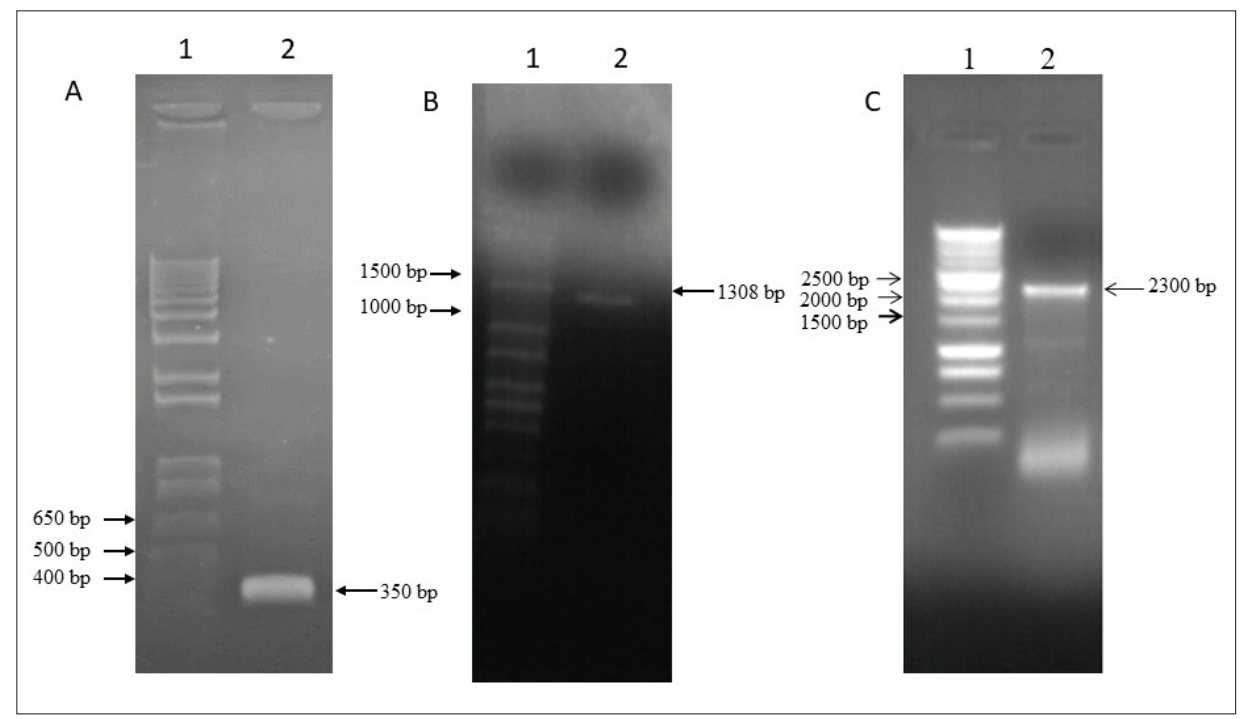

Figure 2: PCR amplification of GluB-1 promoter. A: lane 1 - 1 kb ladder (Invitrogen, USA); lane 2 - 350 bp GluB-1 promoter; B: lane 1 - 100 bp ladder (UC Biotech, Sri Lanka); lane 2 - 1308 bp GluB-1 promoter; C: Lane 1- 1 kb ladder (Promega, USA); Lane 2 - 2300 bp GluB-1 promoter 


\section{RESULTS AND DISCUSSION}

Rice is the staple food for millions of people around the world. Hence, genetic engineering has been focused on improving the grain quality of rice (Ye et al., 2000). The introduction of additional traits through gene stacking requires the use of promoters with differential seed specificity. However, promoters with diverse sequences need to be used to avoid homology-dependent gene silencing, and hence to ensure stable transgene expression (Stam et al., 1997). In addition, patent protection limits the use of non-rice seed promoters in commercial production (Barton \& Berger, 2001). Therefore, the aim of the present work was to determine the potential of different lengths of the GluB-1 promoter $(350 \mathrm{bp}$, $1308 \mathrm{bp}$ and $2300 \mathrm{bp}$ lengths) to drive the expression of a GUS gene. The seeds of a single transgenic plant corresponding to different promoter lengths were selected for the histochemical assay.

\section{Sequence confirmation of different lengths of $G l u B-1$ promoter}

The $350 \mathrm{bp}, 1308 \mathrm{bp}$ and $2300 \mathrm{bp}$ length GluB-1 promoter regions were amplified from genomic DNA of rice variety $\mathrm{Bg} 250$ (Figure 2 ) and cloned into $\mathrm{pGEM}^{\circledR}-\mathrm{T}$ Easy Vector.

The nucleotide sequences of the amplified promoter (2300 bp) showed $99 \%$ identity to Oryza sativa indica group cultivar Shuhui 498 and $98 \%$ identity to Oryza sativa japonica group cultivar Nipponbare. Nucleotide sequence of the $2300 \mathrm{bp}$ length of $G l u B-1$ promoter was deposited in GenBank (accession number MH748577). The endosperm specific cis regulatory elements of GluB- 1 were identified by PLACE promoter analysis as shown in Figure 3.

\section{Generation of transgenic plants and expression of GUS}

A histochemical GUS assay was performed on the seeds, leaf discs and root from a $\mathrm{T}_{0}$ transgenic rice plant transformed with each construct to determine the expression of the GUS reporter gene. The presence of blue colour in the embryo indicated the successful insertion of different lengths of the promoter and its ability to express the GUS reporter gene (Figure 4). The intensity of the blue colour was used as a scale for the level of expression of GUS controlled by the promoter. According to the colour intensity, the promoter efficiency was as follows: $1308 \mathrm{bp}>350 \mathrm{bp}>2300 \mathrm{bp}$ length of GluB-1 promoter. No expression of GUS gene was observed in leaf discs and roots of transgenic plants and the negative control (leaf discs, roots and seeds of nontransgenic rice).

\section{In silico analysis of GluB-1 promoter}

All transgenic rice seeds carrying the promoter/GUS fusions showed expression of the GUS gene. The highest intensity of the colour was observed in transgenic rice seeds containing the $1308 \mathrm{bp}$ promoter/reporter construct indicating higher expression of the GUS gene compared to the other two constructs (Figure 4B).

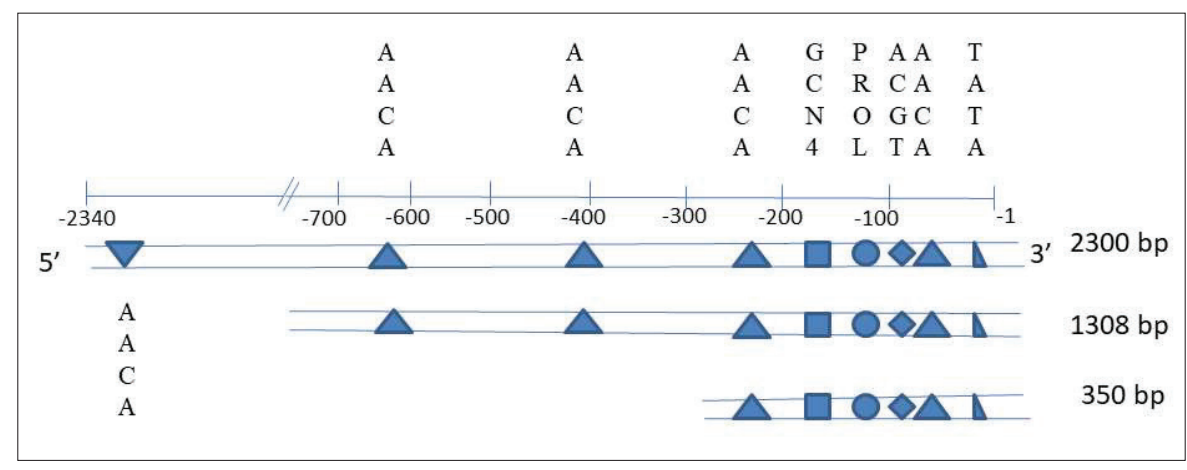

Figure 3: Schematic diagram showing the location of cis elements in different lengths of the GluB-1 promoter. Negative numbers indicate the positions of nucleotides relative to the transcription start site. $\triangle$-AACA motif; $\square$ - GCN4 motif; $\bigcirc$ - Prolamin box; $\diamond$ - ACGT motif; $\bar{\Lambda}$ - TATA box 


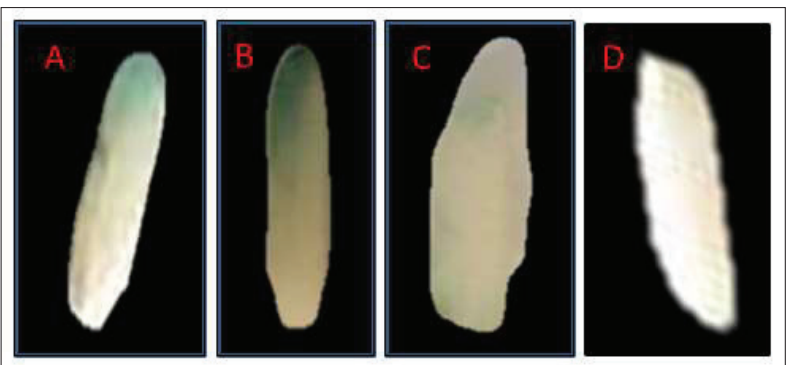

Figure 4: Histochemical analysis of the expression of the GUS gene controlled by different lengths of GluB-1 promoter in transgenic plant seeds: A - 350 bp GluB-1 promoter; B 1308 bp GluB-1 promoter; C - 2300 bp GluB-1 promoter; $\mathrm{D}$ - negative control (non-transgenic $\mathrm{Bg} 250$ rice variety)

The expression of genes is regulated by the combinatorial interactions of multiple cis elements in the promoter. Transcription factors specifically bind to the cis elements that are necessary for transcription initiation of genes. Analysis of the GluB-1 promoter by the PLACE promoter analysis tool revealed the cloned promoters to contain additional AACA motifs upstream of the -197 bp minimal promoter (Figure 3). Wu et al. (1998), demonstrated that the deletion of an extra AACA motif at $-212 \mathrm{bp}$ resulted in an eightfold reduction of promoter activity. It is noteworthy that the $350 \mathrm{bp}, 1308 \mathrm{bp}$ and $2300 \mathrm{bp}$ promoters used in this study were derived from the same GluB-1 promoter sequence, which was able to express the GUS gene. However, the promoter activity was not the same according to the observed colour intensity in histochemical analysis. The promoter activity can be affected by the pattern of the cis elements in the promoter, insertion position and gene dosage of transgenes integrated into the transgenic plant. It

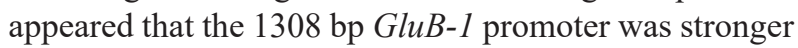
than $350 \mathrm{bp}$ and $2300 \mathrm{bp} \mathrm{GluB-1}$ promoters. The only notable difference in the sequence between the $350 \mathrm{bp}$ promoter and the $1308 \mathrm{bp}$ promoter is the presence of two additional AACA motifs in the 1308 bp promoter starting at position $-413 \mathrm{bp}$ (Figure 3). These extra AACA motifs are likely to be responsible for the increased level of GUS expression in the 1308 bp GluB-1 promoter (Figure 4B).

The GUS activity of the 2300 bp promoter construct was much less compared to the other two constructs (Figure 4C). It may be due to the presence of an AACA motif found in reverse orientation (at -2192 bp) in this construct. Reverse oriented motifs can reduce the GUS activity (Yoshihara et al., 1996; Wu et al., 2000). Yoshihara and co-workers in 1996 reported that the reverse constructs (GCN4 and AACA motifs) decreased the relative GUS activity to about 0.7 in seeds and $\mathrm{Wu}$ et al. (2000) constructed a vector containing reverse oriented sequence between the -245 and -145 bp region containing GCN4 and AACA motifs. This construct was able to direct GUS gene expression in the transgenic rice seeds, although at a lower level than that obtained by the same fragment in the normal orientation, confirming the above. However, CaMV 35S promoter constructs ( -343 to $-46,-209$ to -46 , and -168 to -46 ) with either the forward or the reverse orientation of cis elements had similar GUS expression levels in leaves of Nicotiana tabacum (Fang et al., 2007).

The GUS expression observed for Japonica spp. (Le \& Takaiwa, 2004; Sarker et al., 2015) under the control of the $1300 \mathrm{bp}$ and $2300 \mathrm{bp}$ length GluB-1 promoters were contradictory to the results observed in the present study. GUS gene expression was 10 times higher with the $2300 \mathrm{bp} \mathrm{GluB-1}$ promoter compared to the $1300 \mathrm{bp}$ promoter. It has been attributed to the presence of an extra ACGT motif in the $2.3 \mathrm{~kb}$ promoter. However, this additional ACGT (GTACGTG) motif was absent in Nipponbare (japonica; Accession number: AY427569), Bg 250 (indica; Accession number: MH748577) and Shuhui 498 (indica) rice cultivars. Comparative analysis of the GluB-1 promoter nucleotide sequence of Nipponbare, Bg 250 and Shuhui 498 revealed that one AACA motif (at - 413 bp) was absent in Shuhui 498. Further, other additional motifs such as SORLIP 1(GCCAC) at $-357 \mathrm{bp}$, SORLIP 2 (GGGCC) at $-875 \mathrm{bp}$ and MybSt1 (GGATA) at -228 bp were found within the proximal region of the $G l u B-1$ promoter indica sequences (Bg 250 and Shuhui 498), which were absent in the japonica sequence. These motifs have been identified in various plant promoters with the potential to increase promoter activity (Baranowskij et al., 1994; Hudson and Quail, 2003; Jiao, 2005). An additional GATA box (at $-227 \mathrm{bp}$ ) and E-box (at $-1086 \mathrm{bp}$ ) were also located within the GluB-1 promoter indica sequences (Bg 250 \& Shuhui 498). Previous studies on seed specific promoters suggest that these motifs enhance the expression and tissue specificity of the genes (Kim et al., 2006).

The variation in expression between transgenic rice plants could also be due to 'position effects' that depend on the chromosomal location of transgene insertion, cosuppression, and/or the presence of multiple copies of transgenes (Tang et al., 2003; Donnarumma et al., 2011). However, Nagaya and co-workers reported that position effects are not a major cause of variability of transgene expression in the random integration of a single copy of the transgene in A. thaliana (Nagaya et al., 2005). 


\section{CONCLUSION}

In this study the $G l u B-1$ promoter of rice variety Bg 250 was fully sequenced and in-silico analysed. Combined results of motif analysis and colour intensity of the GUS assay revealed that additional necessary cis elements for seed specific promoter were found within the 1308 bp GluB-1 promoter. Furthermore, a higher expression of GUS in the endosperm was observed with

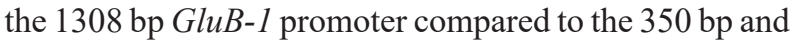
2300 bp GluB-1 promoter. Therefore, the 1308 bp GluB1 promoter appears to be the most suitable promoter for the production of recombinant proteins in the endosperm of rice seeds.

\section{Conflict of interest}

The authors declare that there is no conflict of interests regarding the publication of this study

\section{Acknowledgement}

This research was supported by a grant (RG/2010/BT/04) from the National Science Foundation of Sri Lanka. We thank Ms Dinali Manesha Ranaweera and Nirosha Panchananthan for assistance.

\section{REFERENCES}

Akama K., Kanetou J., Shimosaki S., Kawakami K., Tsuchikura S. \& Takaiwa F. (2009). Seed-specific expression of truncated OsGAD2 produces GABA-enriched rice grains that influence a decrease in blood pressure in spontaneously hypertensive rats. Transgenic Research 18(6): 865-876. DOI: https://doi.org/10.1007/s11248-009-9272-1

Baranowskij N., Frohberg C., Prat S. \& Willmitzer L. (1994). A novel DNA binding protein with homology to Myb oncoproteins containing only one repeat can function as a transcriptional activator. The EMBO Journal 13(22): 5383-5392.

DOI: https://doi.org/10.1002/j.1460-2075.1994.tb06873.x

Barton J.H. \& Berger P. (2001). Patenting Agriculture. Issues in Science and Technology 17(4).

Battraw M.J. \& Hall T.C. (1990). Histochemical analysis of CaMV $35 \mathrm{~S}$ promoter- $\beta$-glucuronidase gene expression in transgenic rice plants. Plant Molecular Biology 15(4): 527-538.

DOI: https://doi.org/10.1007/BF00017828

Choi H.W., Lemaux P.G. \& Cho M.J. (2003). Long-term stability of transgene expression driven by barley endosperm-specific hordein promoters in transgenic barley. Plant Cell Reports 21(11): 1108-1120.

DOI: https://doi.org/10.1007/s00299-003-0630-9
Cornejo M.J., Luth D., Blankenship K.M., Anderson O.D. \& Blechl A.E. (1993). Activity of a maize ubiquitin promoter in transgenic rice. Plant Molecular Biology 23(3): 567-581. DOI: https://doi.org/10.1007/BF00019304

Croissant-Sych Y. \& Okita T.W. (1996). Identification of positive and negative regulatory cis-elements of the rice glutelin Gt3 promoter. Plant Science 116(1): 27-35. DOI: https://doi.org/10.1016/0168-9452(96)04360-9

Donnarumma F., Paffetti D., Fladung M., Biricolti S., Dieter E., Altosaar I. \& Vettori C. (2011). Transgene copy number estimation and analysis of gene expression levels in Populus spp. transgenic lines. BMC Proceedings 5(7): 152-153. DOI: https://doi.org/10.1186/1753-6561-5-S7-P152

Drakakaki G., Christou P. \& Stöger E. (2000). Constitutive expression of soybean ferritin cDNA in transgenic wheat and rice results in increased iron levels in vegetative tissues but not in seeds. Transgenic Research 9(6): 445-452. DOI: https://doi.org/10.1023/A:1026534009483

Fang R.X., Nagy F., Sivasubramaniam S. \& Chua N.H. (1989). Multiple cis regulatory elements for maximal expression of the cauliflower mosaic virus $35 \mathrm{~S}$ promoter in transgenic plants. The Plant Cell 1(1): 141-150. DOI: https://doi.org/10.1105/tpc.1.1.141

Goto F., Yoshihara T., Shigemoto N., Toki S. \& Takaiwa F. (1999). Iron fortification of rice seed by the soybean ferritin gene. Nature Biotechnology 17(3): 282-286. DOI: https://doi.org/10.1038/7029

Higo K., Ugawa Y., Iwamoto M. \& Korenaga T. (1999). Plant cis-acting regulatory DNA elements (PLACE) database: 1999. Nucleic Acids Research 27(1): 297-300. DOI: https://doi.org/10.1093/nar/27.1.297

Holsters M., de Waele D., Depicker A., Messens E., van Montagu M. \& Schell J. (1978). Transfection and transformation of Agrobacterium tumefaciens. Molecular and General Genetics 163(2): 181-187. DOI: https://doi.org/10.1007/BF00267408

Horvath H., Huang J., Wong O., Kohl E., Okita T., Kannangara C.G. \& von Wettstein D. (2000). The production of recombinant proteins in transgenic barley grains. Proceedings of the National Academy of Sciences of the United States of America 97(4): 1914-1919. DOI: https://doi.org/10.1073/pnas.030527497

Hudson M.E. \& Quail P.H. (2003). Identification of promoter motifs involved in the network of phytochrome a-regulated gene expression by combined analysis of genomic sequence and microarray data. Plant Physiology 133(4): 1605-1616. DOI: https://doi.org/10.1104/pp.103.030437

Jefferson R.A. (1987). Assaying chimeric genes in plants: the GUS gene fusion system. Plant Molecular Biology Reporter 5(4): 387-405.

DOI: https://doi.org/10.1007/BF02667740

Jeong H.J. \& Jung K.H. (2015). Rice tissue-specific promoters and condition-dependent promoters for effective translational application. Journal of Integrative Plant Biology 57(11): 913-924. DOI: https://doi.org/10.1111/jipb.12362 
Jiao Y., Ma L., Strickland E. \& Deng X.W. (2005). Conservation and divergence of light-regulated genome expression patterns during seedling development in rice and Arabidopsis. Plant Cell 17(12): 3239-3256. DOI: https://doi.org/10.1105/tpc.105.035840

Kajendran K., Chandrasekharan N.V., Hettiarachchi C.M. \& Wijesundera W.S.S. (2019). Molecular characterization and expression of $\alpha$-gliadin genes from wheat cultivar Dacke in $\mathrm{Bg} 250$ rice variety. GM Crops and Food 10(2): 102-114. DOI: https://doi.org/10.1080/21645698.2019.1622990

Kamenarova K., Gecheff K., Stoyanova M., Muhovski Y., Anzai H. \& Atanassov A. (2007). Production of recombinant human lactoferin in transgenic barley. Biotechnology and Biotechnological Equipment 21(1): 18-27.

DOI: https://doi.org/10.1080/13102818.2007.10817407

Katsube T., Kurisaka N., Ogawa M., Maruyama N., Ohtsuka R., Utsumi S. \& Takaiwa F. (1999). Accumulation of soybean glycinin and its assembly with the glutelins in rice. Plant Physiology 120(4): 1063-1074.

DOI: https://doi.org/10.1104/pp.120.4.1063

Kim M.J., Kim H., Shin J.S., Chung C.H., Ohlrogge J.B. \& Suh M.C. (2006). Seed-specific expression of sesame microsomal oleic acid desaturase is controlled by combinatorial properties between negative cis-regulatory elements in the SeFAD2 promoter and enhancers in the 5'-UTR intron. Molecular Genetics and Genomics 276(4): 351-368.

DOI: https://doi.org/10.1007/s00438-006-0148-2

Le Q.Q. \& Takaiwa F. (2004). Evaluation of tissue specificity and expression strength of rice seed component gene promoters in transgenic rice. Plant Biotechnology Journal 2(2): 113-125.

DOI: https://doi.org/10.1111/j.1467-7652.2004.00055.x

Mena M., Vicente-Carbajosa J., Schmidt R.J. \& Carbonero P. (1998). An endosperm-specific DOF protein from barley, highly conserved in wheat, binds to and activates transcription from the prolamin-box of a native B-hordein promoter in barley endosperm. Plant Journal 16(1): 53-62. DOI: https://doi.org/10.1046/j.1365-313x.1998.00275.x

Müller M. \& Knudsen S. (1993). The nitrogen response of a barley $\mathrm{C}$-hordein promoter is controlled by positive and negative regulation of the GCN4 and endosperm box. Plant Journal 4(2): 343-355.

DOI: https://doi.org/10.1046/j.1365-313X.1993.04020343.x

Nagaya S., Kato K., Ninomiya Y., Horie R., Sekine M., Yoshida K. \& Shinmyo A. (2005). Expression of randomly integrated single complete copy transgenes does not vary in Arabidopsis thaliana. Plant Cell Physiology 46(3): 438444.

DOI: https://doi.org/10.1093/pcp/pci039

Qu L.Q., Xing Y.P., Liu W.X., Xu X.P. \& Song Y.R. (2008). Expression pattern and activity of six glutelin gene promoters in transgenic rice. Journal of Experimental Botany 59(9): 2417-2424.

DOI: https://doi.org/10.1093/jxb/ern110

Ratnayake R.M.L.K. \& Hettiarachchi G.H.C.M. (2010). Development of an efficient Agrobacterium mediated transformation protocol for Sri Lankan rice variety- Bg 250. Tropical Agricultural Research 22(1): 45-53.
DOI: https://doi.org/10.4038/tar.v22i1.2669

Sambrook J. \& Russel D. (2000). Molecular Cloning, 3-volume Set : A Laboratory Manual. Cold Spring Harboc Laboratory Press, USA.

Sarker S., Tammi R.S., Biswas S., Zaman S. \& Seraj Z.I. (2015). Cloning and characterization of a tissue specific promoter GluB-1 from Nipponbare by transformation in rice. Bioresearch Communication 1(2): 69-75.

Shewry P.R. (2007). Improving the protein content and composition of cereal grain. Journal of Cereal Science 46(3): 239-250.

DOI: https://doi.org/10.1016/j.jcs.2007.06.006

Stam M., Mol J.N.M. \& Kooter J.M. (1997). The silence of genes in transgenic plants. Analysis of Botany 79(1): 3-12. DOI: https://doi.org/10.1006/anbo.1996.0295

Sun C. et al. (12 authors) (2010). A simple method for preparation of rice genomic DNA. Rice Science 17(4): 326-329.

DOI: https://doi.org/10.1016/S1672-6308(09)60034-2

Suzuki A., Wu C.Y., Washida H. \& Takaiwa F. (1998). Rice MYB protein OSMYB5 specifically binds to the AACA motif conserved among promoters of genes for storage protein glutelin. Plant and Cell Physiology 39(5): 555-559. DOI: https://doi.org/10.1093/oxfordjournals.pcp.a029404

Takaiwa F., Yamanouchi U., Yoshihara T., Washida H., Tanabe F., Kato A. \& Yamada K. (1996). Characterization of common cis-regulatory elements responsible for the endosperm-specific expression of members of the rice glutelin multigene family. Plant Molecular Biology 30(6): 1207-1221.

DOI: https://doi.org/10.1007/BF00019553

Takaiwa F., Takagi H., Hirose S. \& Wakasa Y. (2007). Endosperm tissue is good production platform for artificial recombinant proteins in transgenic rice. Plant Biotechnology Journal 5(1): 84-92.

DOI: https://doi.org/10.1111/j.1467-7652.2006.00220.x

Takaiwa F. (2013). Increasing the production yield of recombinant protein in transgenic seeds by expanding the deposition space within the intracellular compartment. Bioengineered 4(3): 136-139.

DOI: https://doi.org/10.4161/bioe.24187

Tang J., Scarth R. \& Fristensky B. (2003). Effects of genomic position and copy number of Acyl-ACP thioesterase transgenes on the level of the target fatty acids in Brassica napus L. Molecular Breeding 12(1): 71-81.

Vicente-Carbajosa J., Moose S.P., Parsons R.L. \& Schmidt R.J. (1997). A maize zinc-finger protein binds the prolamin box in zein gene promoters and interacts with the basic leucine zipper transcriptional activator Opaque2. Proceedings of the National Academy of Sciences of the United States of America 94(14): 7685-7690.

DOI: https://doi.org/10.1073/pnas.94.14.7685

Wang S., Takahashi H., Kajiura H., Kawakatsu T., Fujiyama K. \& Takaiwa F. (2013). Transgenic rice seeds accumulating recombinant hypoallergenic birch pollen allergen bet $\mathrm{v} 1$ generate giant protein bodies. Plant and Cell Physiology 54(6): 917-933.

DOI: https://doi.org/10.1093/pcp/pct043 
Washida H., Wu C.Y., Suzuki A., Yamanouchi U., Akihama T., Harada K. \& Takaiwa F. (1999). Identification of cisregulatory elements required for endosperm expression of the rice storage protein glutelin gene GluB-1. Plant Molecular Biology 40(1): 1-12.

Wu C.Y., Suzuki A., Washida H. \& Takaiwa F. (1998a). The GCN4 motif in a rice glutelin gene is essential for endosperm-specific gene expression and is activated by opaque-2 in transgenic rice plants. Plant Journal 14(6): 673-683.

DOI: https://doi.org/10.1046/j.1365-313x.1998.00167.x

Wu C.Y., Adachi T., Hatano T., Washida H., Suzuki A. \& Takaiwa F. (1998b). Promoters of rice seed storage protein genes direct endosperm-specific gene expression in transgenic rice. Plant Cell Physiology 39(8): 885-889. DOI: https://doi.org/10.1093/oxfordjournals.pcp.a029449

Wu C.Y., Washida H., Onodera Y., Harada K. \& Takaiwa F. (2000). Quantitative nature of the prolamin-box, ACGT and AACA motifs in a rice glutelin gene promoter: minimal cis-element requirements for endosperm-specific gene expression. Plant Journal 23(3): 415-421. DOI: https://doi.org/10.1046/j.1365-313x.2000.00797.x

Ye X., Al-Babili S., Klöti A., Zhang J., Lucca P., Beyer P. \& Potrykus I. (2000). Engineering the provitamin A ( $\beta$-carotene) biosynthetic pathway into (carotenoid-free) rice endosperm. Science 287(5451): 303-305.
DOI: https://doi.org/10.1126/science.287.5451.303

Yoshihara T. \& Takaiwa F. (1996). Cis-regulatory elements responsible for quantitative regulation of the rice seed storage protein glutelin GluA-3 gene. Plant and Cell Physiology 37(1): 107-111.

DOI: https://doi.org/10.1093/oxfordjournals.pcp.a028907

Yoshihara T., Washida H. \& Takaiwa F. (1996). A 45-bp proximal region containing AACA and GCN4 motif is sufficient to confer endosperm-specific expression of the rice storage protein glutelin gene, GluA-3. FEBS Letters 383(3): 213-218.

DOI: https://doi.org/10.1016/0014-5793(96)00233-5

Yoza K., Imamura T., Kramer K.J., Morgan T.D., Nakamura S., Akiyama K., Kawasaki S., Takaiwa F. \& Ohtsubo K. (2005). Avidin expressed in transgenic rice confers resistance to the stored-product insect pests Tribolium confusum and Sitotroga cerealella. Bioscience, Biotechnology and Biochemistry 69(5): 966-971.

DOI: https://doi.org/10.1271/bbb.69.966

Zheng Z., Kawagoe Y., Xiao S., Li Z., Okita T., Hau T.L., Lin A. \& Murai N. (1993). 5' Distal and proximal cis-acting regulator elements are required for developmental control of a rice seed storage protein glutelin gene. The Plant Journal for Cell and Molecular Biology 4(2): 357-366. DOI: https://doi.org/10.1046/j.1365-313X.1993.04020357.x 